\title{
APONTAMENTOS SOBRE O SIGNIFICADO DE MEMÓRIA E VERDADE NO LEGADO DA DITADURA CIVIL-MILITAR BRASILEIRA
}

\author{
Notes on the meaning of memory and truth in the \\ legacy of the Brazilian civil-military dictatorship
}

\author{
Rafael L. F. C. Schincariola
}

\begin{abstract}
Resumo O direito à memória e à verdade são pilares da Justiça de Transição, utilizada, desde 2009, pelo Estado brasileiro, como categoria central para lidar com o legado autoritário da ditadura civil-militar (1964-1985). A Justiça de Transição oferece, assim, um amplo repertório para que países confrontem seu passado violento. No entanto, pesquisas recentes demonstram limitações da categoria e de seu uso. Essas críticas têm sido pouco trabalhadas no debate e em sua aplicação no país. Com base em uma visão crítica da categoria de Justiça de Transição e na observação empírica das especificidades do caso brasileiro, este artigo pretende problematizar essas questões de um ponto de vista analítico, demonstrando como as noções de memória e verdade devem ser abordadas em uma perspectiva mais refinada.
\end{abstract}

Palavras-chave memória e verdade; justiça de transição; Direitos Humanos; democracia; ditadura civil-militar brasileira.

\begin{abstract}
The Right to Memory and Truth are pillars of the concept of Transitional Justice, which has been used since 2009 by the Brazilian government as a central category for dealing with the authoritarian legacy of civil-military dictatorship (1964-1985). The category Transitional Justice offers a broad repertoire for countries confront their violent past. However, recent research demonstrates the limitations of the concept and its use. These critiques have not been worked in the debate about the concept and its application in Brazil. Based on a critical view of the concept, Transitional Justice and the empirical observation on the specificities of the Brazilian

a Coordenador da Comissão Especial sobre Mortos e Desaparecidos Políticos - primeira comissão de Estado criada para lidar com o legado da ditadura -, desempenhando, entre outras, a função de coordenação do Grupo de Trabalho Araguaia e do Grupo de Trabalho Perus, que são encarregados, respectivamente, (1) das buscas dos desaparecidos políticos da guerrilha do Araguaia e (2) da avaliação das ossadas encontradas na Vala Clandestina de Perus, com vistas a identificar desaparecidos. É doutor em Direito pela Universidade de São Paulo e, atualmente, realiza pesquisa de pós-doutoramento em Ciência Política na mesma instituição.
\end{abstract}


case, this article aims to problematize these issues in an analytical point of view, showing how notions of memory and truth must be addressed in a more refined perspective.

Keywords truth and memory; transitional justice; Human Rights; democracy; Brazilian civil-military dictatorship.

\section{INTRODUÇÃO}

De 1964 a 1985, o Brasil esteve sob a égide de uma ditadura civil-militar, que se distinguiu principalmente por praticar, favorecer e permitir diversas formas de violência contra a pessoa humana. $O$ contexto se caracterizou, sobretudo, pela supressão de direitos constitucionais, censura, perseguição política e repressão aos que eram contrários ao regime autoritário, que, por sua vez, foram exilados, presos, torturados, assassinados e ficaram desaparecidos.

A transição para a democracia, no entanto, foi lenta. Iniciou-se ainda em meio a torturas e à repressão, desencadeando-se até 1974, com destaque para a revogação do AI-5. Em 1979, um segundo passo foi dado com a promulgação da Lei 6.638, conhecida como a Lei da Anistia. Nos anos 1983-1984, o movimento “Diretas Já!” termina por conseguir que um presidente civil seja eleito pelo colégio eleitoral. A última grande etapa desse processo de redemocratização é cumprida somente com a promulgação da Constituição de 1988, rígida para garantir a inderrogabilidade de direitos e as garantias fundamentais, propalada como "Constituição cidadã", que funda um Estado democrático de Direito no Brasil.

Esse processo "lento, gradual e seguro", para utilizar a expressão consagrada por um ditador, ocorreu sem a derrota efetiva do regime autoritário, na medida em que foi conduzido pelos próprios militares, auxiliando a construção de uma ideia que é fundamental para compreender as dificuldades encontradas historicamente para lidar com o legado do estado de exceção: a ideia de que se vivia em um Estado legal e que, nessa medida, havia dois lados lutando em uma guerra pelo poder - enquanto, como se sabe, tratava-se de um Estado que perseguiu e aniquilou seus próprios cidadãos. Tais fatos se somam a outros elementos que tornaram extremamente difícil o desnudamento sobre a verdade das violações de direitos humanos ocorridas no Estado de exceção.

Nesse sentido, pode-se afirmar que o Brasil avançou muito nos últimos anos. A esfera pública brasileira está tomada pelo debate sobre o direito à memória e à verdade. Lançado em dezembro de 2009, por meio de decreto, o Terceiro Programa Nacional de Direitos Humanos é o primeiro desses programas que previu o 
respeito ao direito à memória e à verdade, nas diretrizes 23 a 26 (BRASIL, 2009b). Além disso, definiu a criação de um grupo de trabalho incumbido de elaborar um projeto de lei para a criação de uma Comissão da Verdade, competente para investigar os crimes da ditadura. Foi desse contexto histórico e político que surgiu a Comissão Nacional da Verdade (CNV). Durante os debates sobre o projeto de lei que criava essa comissão, e também após sua instalação, o país passa a viver um período especial, pelo menos no que tange ao debate sobre a garantia do direito à memória e à verdade.

Desde 2009, a categoria Justiça de Transição vem sendo usada pelo Estado brasileiro. Hoje, a Justiça de Transição, que traz em seu bojo os direitos à memória, à verdade e à justiça, veiculada acadêmica e politicamente de forma ampla entre setores ligados aos Direitos Humanos, vem impulsionando o desenvolvimento de políticas para lidar com o legado da ditadura. No entanto, sua aplicação no Brasil vem sendo feita de forma assistemática e sem a consideração das críticas que são dirigidas tanto à categoria quanto à sua aplicação prática, que acusam limitações teóricas e atacam, de um lado, a normatividade e, de outro, a maneira como a categoria é tratada como universalizável para distintos contextos. Nesse âmbito, o direito à memória e à verdade é tido de modo demasiadamente específico e excludente. Este artigo pretende, justamente, contextualizar de forma crítica o uso da categoria no Brasil, nos últimos anos, e, a partir da observação das especificidades do caso brasileiro, problematizá-la de um ponto de vista analítico, demonstrando como as noções de memória e verdade devem ser abordadas sob uma perspectiva mais refinada quanto à Justiça de Transição.

\section{JUSTIÇA DE TRANSIÇÃO}

Justiça de Transição é um conceito relativamente novo, que se refere a como sociedades devem lidar com o legado de violência e violações de Direitos Humanos após um período de conflito, guerra civil, genocídio, terrorismo de Estado e outras formas de severo trauma social. Basicamente, consiste em processos e mecanismos necessários para o (r)estabelecimento do Estado de Direito, para a prestação de contas no que tange às violações de direitos humanos e para a consolidação da democracia (Bickford, 2004; ICTJ, 2008; Teitel, 2003, United Nations Security Council, 2004; ZyL, 2009).

São vários os objetivos da justiça transicional, em um contexto global, e eles podem ser agrupados da seguinte maneira, à guisa de sistematização: diferenciar e distanciar o novo regime das práticas do anterior, com o intento de construir 
um futuro mais democrático e pacífico, evitando a repetição da violência; fornecer reparações às vítimas, revelar a verdade sobre crimes do passado, reformar as instituições perpetradoras do abuso, processar os agentes responsáveis e promover a reconciliação; e promover iniciativas de paz, reconciliação e democracia, restaurando o Estado de Direito e consolidando a democracia.

Para que isso ocorra, contudo, uma combinação de estratégias judiciais e não judiciais é recomendada ao Estado. A primeira iniciativa seria, então, processar os perpetradores de crimes contra os Direitos Humanos. Essa tarefa deve envolver a "responsabilização dos agentes de Estado que cometeram graves violações de Direitos Humanos, como a tortura, os homicídios, os estupros, os sequestros, as ocultações de cadáveres, além de tantos outros crimes" (MÉNDez, 2007).

É necessário, a partir disso, que o Estado encampe uma acirrada busca pela verdade. "Uma comissão da verdade pode ser definida como órgão estabelecido para investigar determinada história de violações de Direitos Humanos" (MezAROBBA, 2010, p. 32). As comissões podem servir de resposta não só às violações do passado, mas também, e, sobretudo, aos abusos ainda presentes, ou seja, ao que restou do período ditatorial, na medida em que devem auxiliar a combater a impunidade, acentuar a responsabilidade do Estado e recomendar reformas do aparato institucional (HAYNER, 2002, p. 11 e ss.).

Outra iniciativa consistiria nos chamados Programas de Reparação, pois é necessária a reparação das vítimas que sofreram perseguições e tiveram prejuízos com a situação de conflito, sejam eles de caráter material, sejam psicológicos. Essa reparação pode ser econômica (pagamento de bolsas, pensões, etc.), psicológica (aconselhamento ou terapia para lidar com o trauma) ou ocorrer, ainda, por intermédio de medidas simbólicas (construção de monumentos, museus e memoriais e criação de dias de comemoração nacionais).

Outro desafio que deve ser enfrentado é reformar ou dissolver as instituições que estavam conectadas às práticas abusivas, com o intuito de prevenir futuras violações e democratizar efetivamente as instituições. Esse processo deveria ocorrer, por exemplo, na reforma da polícia e dos órgãos de segurança pública, das instituições militares e do Sistema de Justiça. Isso inclui, inclusive, a remoção de pessoas que violaram os Direitos Humanos de cargos públicos.

Importante destacar que a categoria de Justiça de Transição é considerada uma nova disciplina no campo dos Direitos Humanos (ANDRIEU, 2010), que vem ganhando cada vez mais importância. Em um período curto de tempo, tem dominado os debates na "intersecção entre democratização, proteção aos Direitos Humanos e reconstrução do Estado após conflitos" (McEvor, 2008, p. 15). De 
acordo com Olsen (2010a), mais de 126 países aplicaram ou estão aplicando pelo menos um dos mecanismos sugeridos pela Justiça de Transição.

\section{CRÍTICAS AO CONCEITO}

Antes de continuar, é imperativo destacar que Justiça de Transição não é uma categoria analítica forte e completa, haja vista que ainda está em desenvolvimento e disputa no campo das Ciências Humanas e das Ciências Sociais aplicadas. Isso faz com que a abordagem sobre ela seja complicada, na medida em que suas fronteiras ainda não foram efetivamente definidas (OKELlo, 2010). Mesmo envolvendo dois conceitos, justiça e transição, a literatura especializada sobre o assunto não analisa satisfatoriamente o significado deles.

De um lado, a literatura não discute adequadamente o conceito de transição; de outro, foca nas estratégias que trariam justiça, e não propriamente na definição do conceito. A categoria trata, sem muita diferenciação, todas as mudanças a que uma sociedade e/ou Estado está sujeito após diferentes situações de violência: guerra civil, genocídio, Estado autoritário, etc. Isso a enfraquece, pois a torna muito ampla e imprecisa. Além disso, o termo transição traz confusão ao conceito, pois, muitas vezes, suas estratégias e seus mecanismos são utilizados não necessariamente no período de transição, mas após ela ocorrer. Reconciliação e democracia, outros conceitos importantes no debate, também são definidos de maneira vaga.

Reconciliação é um conceito tratado como universalizável, o qual toda a sociedade que passou por situações de graves violações de Direitos Humanos e conflitos deve buscar, como mecanismo para chegar à democracia e à paz social. Ou seja, reconciliar deveria ser utilizado em pelo menos dois cenários muito distintos: um, no qual a radicalização da violência alcançou uma expressão que dividiu a sociedade em pelo menos dois grupos, que assim deveriam se reconciliar; outro, no qual houve um Estado perpetrador de graves violações, de forma indistinta, contra seus cidadãos. Pelo menos na segunda situação, não há sentido no reconciliar, pois não há sujeito para a reconciliação, já que o Estado foi o agente criminoso. A carência de uma melhor especificação do que se entende por reconciliar, em diferentes conjunturas, empobrece o uso do conceito na categoria Justiça de Transição. Já a noção de democracia é colocada como objetivo orientador de todas as ações relacionadas ao processo de transição. No entanto, não há uma consonância sobre o que se entende por democracia, atualmente. De maneira geral, predomina a ideia de que se tem democracia quando há, nas instituições políticas de um país, uma 
democracia liberal formal, isto é, garantias mínimas de igualdade jurídica para votar, aliada à regra da maioria.

McEvoy (2008) chama a atenção para a predominância do legalismo na construção da categoria de Justiça de Transição, o que o mantém dominado pelas estreitas lentes das construções jurídicas. A maneira como são abordados os Direitos Humanos também traz problemas dentro desse debate. Especialistas apontam que as estratégias da categoria são muito seletivas e excludentes, já que consideram violações de Direitos Humanos apenas ofensas a direitos civis e políticos: "foca [a Justiça de Transição] em formas particulares de abuso, intervalos de tempo e categorias de perpetradores específicos" (Merwe, 2009, p. 117). Dessa forma, mesmo sendo a Justiça de Transição uma categoria inserta nos Direitos Humanos, não há uma preocupação em garantir a reparação de todas as formas de opressão que se sucederam, em um Estado de violência.

Nesse sentido, há uma interpretação conservadora que ignora questões sociais e econômicas, bem como o sofrimento advindo da experiência de ausência de liberdades. Além disso, suas estratégias tendem a desconsiderar relações políticas, econômicas, sociais e internacionais que causaram as violações, pois o foco está exatamente nessas, e não necessariamente no contexto que possibilitou que as violações ocorressem. Isso faz com que a busca pela garantia dos Direitos Humanos seja incompleta.

Há críticas, também, quanto à normatividade e universalidade do modelo, fortemente influenciado por uma perspectiva liberal, digamos assim, que delineia estratégias de democratização com base em paradigmas que poderiam ser utilizados em distintas conjunturas (QuinalHA, 2012). Isso faz com que a Justiça de Transição seja operada como uma combinação de mecanismos padrões preestabelecidos, e assim acabe por ser reduzida a uma "caixa de ferramentas". Dessa maneira, elementos universais estariam disponíveis para serem utilizados por diferentes atores, em diferentes realidades.

Como a mediação entre o universal e o particular não existe na teorização acerca da categoria, isso gera um casuísmo na aplicação dos mecanismos. Com efeito, esse uso da Justiça de Transição faz com que exista o risco da transposição de uma normatividade de um contexto a outro, com a apreciação equivocada de distintos processos e com desprezo a particularidades (Cf. BeLl, 2009; GreifF, 2010; Leebaw, 2008; Merwe; Baxter; Chapman, 2009; Nagy, 2008; Olsen; Payne; Reiter, 2010b; Palmer; Clark; Granville, 2012; Quinalha, 2012). 
Somam-se a essas críticas os desafios que comumente se apresentam quando da aplicação dos mecanismos da Justiça Transicional. Esses desafios podem ser elencados da seguinte forma:

a) Fornecer legitimidade e sentimento de pertença dos locais, que "são essenciais para a eficácia das instituições sociais” (RAMJI-NogalEs, 2010; AIV; CAVv, 2009; FleTChER et al., 2009; LUTZ, 2006).

b) Assegurar transparência dos processos e garantir, com efeito, um alcance maior de suas ações (VInck; РнAм, 2010).

c) Os mecanismos devem ser parte da reconstrução e consolidação do Estado Democrático de Direito (HAIDER, 2011).

d) Tendo em vista que há dificuldade em determinar o momento apropriado para a aplicação dos mecanismos, deve-se encontrar a maneira mais apropriada de combiná-los (FLETCher et al, 2009).

Essa sistematização das críticas que se dirigem tanto à categoria quanto à aplicação de seus mecanismos permite refletir sobre o necessário cuidado para o uso da categoria de Justiça de Transição e de suas estratégias, em contextos específicos.

\section{JUSTIÇA DE TRANSIÇÃO NO BRASIL}

Com base nas prescrições dessa categoria - Justiça de Transição -, após mais de duas décadas do fim da ditadura, o Estado brasileiro pouco fez para lidar com o espólio autoritário da ditadura civil-militar (1964-85) (PAYNE, 2008; ABRÃo; Torelly, 2010). Os principais passos dados pelo Estado para lidar com o legado de violações dos Direitos Humanos foram três até então. Houve, em um primeiro momento, a promulgação da Lei 9.140/1995, pela qual o Estado reconheceu como mortas as pessoas desaparecidas em razão de sua participação, ou acusação de participação, em atividades políticas, no período de 02 de setembro de 1961 a 15 de agosto de 1979. Depois, ocorreu a promulgação da Lei 10.559/2002, que deu corpo à Medida Provisória que instituiu a Comissão da Anistia (o programa de reparação brasileiro). Atualmente, essa Comissão tem levado a cabo grande parte dos esforços para a realização da Justiça de Transição no Brasil. Por último, houve a promulgação da Lei 12.528/2011, que criou a Comissão Nacional da Verdade, encarregada de apurar as violações de Direitos Humanos, em um período que inclui a ditadura civil-militar. 
Pode-se dizer que, até o momento, o saldo do "acerto de contas" é escasso. O Estado brasileiro reconheceu sua responsabilidade na morte e no desaparecimento de (apenas) 434 pessoas, sendo 191 mortas e 210 desaparecidas (BRASIL, 2014) ${ }^{1}$. No entanto, de acordo com relatórios encaminhados à $\mathrm{CNV}$, esse número tende a ser muito maior (ZELIC, 2012). Apesar do reconhecimento da responsabilidade em mortes e desaparecimentos forçados, apenas 33 restos mortais foram localizados e identificados.

Os esforços do Estado se concentram, hoje, na atuação de dois grupos de trabalho. Em 2009, por meio da Portaria n. 567, foi criado o Grupo de Trabalho Tocantins (GTT), coordenado pelo Ministério da Defesa (MD). Em 2011, esse grupo foi reformulado, passando a se chamar Grupo de Trabalho Araguaia (GTA) e contando também com a participação do Ministério da Justiça e da Secretaria de Direitos Humanos da Presidência da República, nos termos da Portaria Interministerial $n^{0}$ 1.102, de 05 de junho de $2012^{2}$. Esse grupo de trabalho foi reestruturado em 2014, pela Portaria Interministerial no 1540, de o8 de setembro de 2014. Segundo a nova configuração, a Secretaria de Direitos Humanos da Presidência da República assume a coordenação-geral dos trabalhos, enquanto o Ministério da Defesa se incumbe da logística, e o Ministério da Justiça, da perícia. O objetivo fundamental do GTA é localizar, recolher e identificar os corpos de guerrilheiros mortos no episódio conhecido como Guerrilha do Araguaia. O outro Grupo de Trabalho é incumbido de cuidar do processo de identificação de desaparecidos políticos cujos corpos podem estar entre as ossadas descobertas na Vala Clandestina do Cemitério Dom Bosco, em Perus, no Município de São Paulo. O Grupo de Trabalho Perus (GTP), inclusive, foi criado por meio da Portaria da Ministra de Estado Chefe da Secretaria de Direitos Humanos no 620, de o9 de outubro de $2014^{3}$.

O Estado brasileiro também estabeleceu um programa de reparação financeira para vítimas da ditadura ou suas famílias e instalou a CNV para revelar a

1 A Comissão Especial sobre Mortos e Desaparecidos Políticos havia reconhecido 363 vítimas fatais da ditadura (BRASIL, 2009a). A Comissão Nacional da Verdade aumentou esse número para 434, em seu relatório final.

2 O GTT foi criado para atender a condenação da União, na Ação Ordinária no $820024682-5$, da $1^{\text {a }}$ Vara Federal de Brasília-DF. O GTA foi criado para atender essa sentença e, ainda, a decisão da Corte Interamericana de Direitos Humanos, no caso Gomes Lund e outros envolvendo o Brasil.

3 Para a realização desse trabalho, foi contratada uma equipe multidisciplinar formada por arqueólogos forenses, antropólogos, bioarqueólogos, historiadores e fotógrafos. Integram o quadro de profissionais peritos oficiais brasileiros, vinculados à Secretaria Nacional de Segurança Pública, à Associação Brasileira de Antropologia Forense e à Polícia Federal. Em 2015, serão realizados os primeiros exames de DNA de amostras extraídas das ossadas analisadas. Esse trabalho busca, também, o fortalecimento de políticas públicas contra o desaparecimento e o fortalecimento da antropologia forense na área dos Direitos Humanos. 
verdade sobre as violações de Direitos Humanos durante o regime autoritário ${ }^{4}$. No entanto, nenhum agente envolvido em crimes contra a humanidade foi punido até então, seja penalmente (em virtude do bloqueio imposto pela Lei de Anistia), seja administrativamente (vetting). A Lei de Anistia, de acordo com a interpretação oficial, garantiu anistia aos agentes públicos que cometeram crimes durante a ditadura. A Ordem dos Advogados do Brasil (OAB) ingressou com uma Arguição de Descumprimento de Preceito Fundamental, n. 153, com o intuito de alterar tal interpretação, a fim de que os agentes públicos fossem julgados (CONSELHO FEDERAL DA OAB, 2008). Em 2010, o Supremo Tribunal Federal (STF) negou provimento à ação. Em dezembro do mesmo ano, a Corte Interamericana de Direitos Humanos invalidou a Lei de Anistia brasileira, na decisão do "Caso Araguaia”. No entanto, até o momento, o Estado brasileiro não cumpriu a sentença da Corte. Juízes federais chegaram a aceitar denúncias contra agentes públicos por alegados crimes durante a ditadura - acataram a tese de que, como os corpos de algumas vítimas nunca foram encontrados, os casos de sequestro permanecem em aberto e, assim, não estão sujeitos à Lei de Anistia (Brasil, 2010; CIDH, 2010; MEYER, 2012; MPF, 2013). Inclusive, a CNV, em seu relatório, pede a punição dos agentes perpetradores de graves violações de Direitos Humanos.

Ademais, não há nenhum programa de reparação psicológica, e as medidas relativas à reparação simbólica ${ }^{5}$ ainda não começaram a se alastrar. O programa de reparação, é certo, apresenta avanços no aspecto imaterial e memorialístico com as Caravanas da Anistia, que consistem em sessões públicas para anistiar os beneficiários, nas quais o Estado pede oficialmente perdão pelos seus crimes (ABrÃo; Torelly, 2010, p. 52 e ss.). Mas o fato é que os esforços memorializantes, digamos assim, são ainda bastante tímidos ${ }^{6}$, e, no plano mais concreto, as instituições de segurança, a Polícia e o Exército, não foram reformadas.

4 A Comissão Nacional da Verdade iniciou seus trabalhos em 16 de maio de 2012 e encerrou-os no dia 10 de dezembro de 2014, com a entrega do relatório final, em cerimônia oficial no Palácio do Planalto, à presidenta Dilma Rousseff.

5 Há de serem destacados os esforços recentes da Comissão de Anistia, com a criação das Clínicas do Testemunho, para atendimento psicológico de vítimas da ditadura, e da Comissão Especial sobre Mortos e Desaparecidos Políticos, que, no âmbito do Grupo de Trabalho Perus, vem estabelecendo uma relação antropológica e psicologicamente estabelecida com familiares de possíveis inumados na Vala de Perus.

6 Só há um espaço oficial de Memória: o Memorial da Resistência de São Paulo. Há previsão para a construção do Memorial da Anistia, em Belo Horizonte, e do Memorial pela Justiça e Liberdade, em São Paulo. Enquanto isso, o Brasil tem quase mil escolas, inúmeras cidades e espaços públicos com nomes de "presidentes" da ditadura civil-militar. Não existem datas comemorativas nacionais em respeito às vítimas da ditadura, além do fato de que os clubes militares insistem em comemorar a "Revolução de 1964". 
O Estado brasileiro passou a utilizar, em 2009, o termo Justiça de Transição para lidar com a violência pregressa. No final do mesmo ano, foi lançado o III Plano Nacional de Direitos Humanos, o qual trouxe pela primeira vez um eixo dedicado ao Direito à Memória e à Verdade. Desde então, o uso do termo Justiça de Transição trouxe ganhos políticos e jurídicos, pois o debate acerca do "que resta da ditadura" foi enriquecido, adentrando na pauta política. Nesse período, pode-se dizer que alguns avanços ocorreram - o maior deles, certamente, foi a criação da CNV7.

No entanto, o uso do termo, em sua forma tradicional, sem a observância das críticas direcionadas a ele e sem a avaliação do contexto de aplicação de seus mecanismos, impede que seja delineada uma estratégia mais clara e acabada do que significa lidar, de fato, com o legado autoritário brasileiro. Isso ocorre, principalmente, por conta de alguns motivos que seria interessante serem mencionados.

A abordagem tradicional da categoria permite que direitos relativos à violência do passado (justiça, memória, verdade, reparação e reforma institucional) e a seus mecanismos sejam teorizados e operacionalizados de maneira compartimentada, $\mathrm{e}$ não de forma conjunta. No caso brasileiro, o foco maior reside na discussão sobre a responsabilização criminal dos agentes públicos e, mais recentemente, também no debate sobre o direito à verdade. Outras formas de responsabilização e outros direitos não são priorizados, tais como a reparação psicológica, os esforços memorializantes e a reforma das instituições de segurança.

Nessa medida, o entendimento sobre a justiça é limitado, uma vez que ela é compreendida essencialmente como uma categoria criminal. Assim, somente se considera um grupo seletivo e limitado de perpetradores e responsáveis pelos crimes da ditadura. $\mathrm{O}$ uso tradicional da categoria Justiça de Transição traz também outro problema: o da aplicação de mecanismos preestabelecidos e

7 Ademais, na esteira da criação da CNV, intensificou-se a luta por memória, verdade e justiça na sociedade civil. Em 2011, já haviam sido criados diversos comitês estaduais para reivindicar os direitos à memória, à verdade e à justiça. Em 2012, manifestações foram organizadas por esses comitês. Houve, também, protestos organizados por outros setores da sociedade civil organizada. Uma série de "escrachos", ou "esculachos", organizados principalmente pelo Levante Popular da Juventude, ganhou corpo. Os escrachos consistem em denunciar o endereço de uma ou mais pessoas que participaram de crimes durante a ditadura, mostrando aos vizinhos e aos transeuntes que, naquele determinado local, reside um antigo colaborador do regime autoritário. No site do youtube, podem ser encontradas diversas dessas ações. No mesmo contexto, diversos movimentos sociais se congregaram e formaram o grupo chamado "Cordão da Mentira”. O primeiro ato desse grupo foi um carnaval fora de época, no dia $1^{\circ}$ de abril, com o tema "Quando vai acabar a ditadura civil-militar?”, para protestar contra os resquícios da ditadura civil-militar e exigir o direito à memória, à verdade e à justiça. É interessante frisar, também, que a criação da Comissão da Verdade gerou também um "efeito cascata", na luta pelo direito à verdade. Atualmente existem mais de uma centena de comissões da verdade (estaduais, municipais e institucionais) espalhadas pelo Brasil. 
utilizados em diferentes contextos, sem que seja pensado como eles deveriam ser institucionalizados diante do contexto específico da ditadura civil-militar brasileira. Não há critério algum para a definição de quais mecanismos e estratégias deveriam ser aplicados e de quando deveriam ser aplicados.

A falta de definição de como a categoria vai ser utilizada faz com que, por exemplo, um conceito como o de reconciliação perdure no debate nacional, mesmo desgastado semanticamente pelo largo uso que fizeram dele os militares para justificar a não efetivação dos direitos ligados à Justiça de Transição - "remexer no passado" traria o "perigo do retrocesso", diziam. Importante ressaltar, nesse sentido, que a reconciliação, um dos objetivos mais importantes de Justiça de Transição, não parece se encaixar no caso brasileiro, porque o país não tinha, na época da ditadura, uma sociedade dividida - não tínhamos um apharteid ou alguma situação similar. Não houve uma guerra, mas sim um ataque do Estado contra seus cidadãos. Se existiu, ou existe ainda, alguma divisão na sociedade brasileira, ela é caracterizada por outras dimensões, entre a elite e a "patuleia”, entre os ricos e os pobres, entre os brancos e os negros, apenas para ficar em alguns exemplos.

Como querem alguns, não é uma estratégia interessante renovar o conceito de reconciliação, no sentido de que reconciliar seria "reformar as instituições", "garantir a verdade" e efetivar outros objetivos da Comissão da Verdade (que traz em seu bojo, é bom lembrar, o objetivo da reconciliação). Isso porque o termo já tem apegado a si uma significação histórica. Políticos e militares mais conservadores usam essa expressão para justificar a não necessidade (e o perigo) de olhar para o passado, porque o sucesso da democracia depende, para eles, da transição, com base nessa "reconciliação", que já teria sido efetivada com a malfadada transição "lenta, gradual e segura".

Da mesma forma, a consolidação da democracia, objetivo aberto na categoria Justiça de Transição, permanece obscura, quando pensada para o caso brasileiro. Questões históricas que remontam à compreensão da motivação do golpe militar e da sustentação e do financiamento da ditadura, que envolvem o rastro político-econômico-social-internacional que imprimiu a força autoritária, permanecem tímidas no debate. A participação de camadas da sociedade civil na ditadura, por exemplo, é algo ainda por ser devidamente explorado. A literatura sobre o tema ainda negligencia o papel dos empresários na liderança política dos acontecimentos, na definição de diretrizes políticas e táticas, empregadas para enfrentar a resistência ao regime. A Operação Bandeirante, por exemplo, que não dispunha de verbas consignadas em orçamento, foi financiada por empresas privadas. Antonio Delfim Netto e Gastão Vidigal, dono do Banco Mercantil de São Paulo, 
encarregaram-se de pedir verbas aos grandes bancos e às empresas, por meio da FiEsP. Participaram do financiamento, entre outras empresas, o grupo Ultragás com destaque para a participação fundamental de seu presidente, Albert Boilesen, que, inclusive, participava das torturas -, a Ford e a Volskwagem (que forneciam carros), a General Motors, a Supergel (que fornecia comida congelada), o Banco Bradesco, o Grupo Objetivo e a Folha da Tarde, que, por publicar na íntegra as notas redigidas por órgãos repressivos, era considerada o "Diário Oficial da Operação Bandeirante" (cf. WeICHERT, 2011; Arns, 1990, p. 72; GASPARI, 2002, p. 60 e ss.).

Aliás, a Operação Condor, aliança político-militar entre os vários regimes militares da América do Sul - Brasil, Argentina, Chile, Bolívia, Paraguai e Uruguai -, criada com o objetivo de coordenar a repressão a opositores dessas ditaduras e eliminar, com isso, líderes de esquerda instalados nos seis países do Cone Sul, também é pouco tematizada, assim como a participação dos Estados Unidos da América (EUA) no golpe e na ditadura. O mesmo ocorre com as consequências de uma transição "lenta, gradual e segura" (CODATO, 2006; Comparato, 2009; FERnANDES, 1986) e a aparência de legalidade do regime, que teriam legado ao país uma dificuldade enorme em tematizar e garantir os direitos da Justiça de Transição.

A violência policial (das instituições de segurança em geral) continua a assolar a população, sem que isso seja tratado como um problema ligado à Justiça de Transição. A Polícia Militar (PM) mata em torno de duas mil pessoas anualmente. As PMs do Rio de Janeiro e de São Paulo estão implicadas em pelo menos onze mil execuções extrajudiciais - sendo que jovens, negros e pobres são o principal alvo. Parte desses assassinatos foi cometida por esquadrões da morte, "grupos de extermínio", formados por policiais. Enfim, a tortura é um problema crônico em nosso país, principalmente nas prisões, e aumentou após o período ditatorial, segundo algumas instituições de Direitos Humanos (Amnesty InTERnATIONAL, 2013; Human Rights Watch, 2013, Nev, 2012; Network for Social Justice and Human Rights, 2012; Pastoral Carcerária, 2010; Safatle; Teles, 2010; United Nations Human Rights Council, 2012). O Núcleo de Estudos da Violência da Universidade de São Paulo (NEV-USP), em seu relatório sobre a continuidade autoritária, de 1999, e em outros textos de seus membros, foi pioneiro e um dos poucos a afirmar a necessidade de combater a lógica da polícia advinda do período autoritário, tratando-a expressamente como um dos maiores legados da ditadura. A novidade mais atual nesse campo foi a recomendação, no relatório da Comissão Nacional da Verdade, de que as polícias estaduais sejam desmilitarizadas (BRASIL, 2014).

Ao lado desse panorama, o Poder Judiciário também não assumiu responsabilidade por seu papel na ditadura, e segue conservador e autoritário em inúmeros 
aspectos (Cf. PEREIRA, 2010). Conforme afirma Baggio (2010, p. 296), a “perpetuação de uma cultura jurídica autoritária não se restringe às dificuldades em se apurar os fatos ocorridos ao longo do regime ditatorial ou às resistências em responsabilizar os agentes estatais violadores dos Direitos Humanos”. Essa cultura alcança a realidade atual, com procedimentos jurídicos repletos de autoritarismos, ausentes de constitucionalidade e com discursos conservadores. Além disso, o Judiciário é uma das poucas instituições que não criou uma comissão da verdade própria e não vem debatendo o legado da ditadura institucionalmente.

Assim, a ausência de um programa normativo definindo o que se deve entender por Justiça de Transição no Brasil faz com que parte das estratégias e dos mecanismos da categoria não seja debatida de forma ampla, que a implementação dos mecanismos e estratégias fique sem prescrição, sobretudo quanto ao tempo e à forma, e que, quando implementados, corram o risco de que isso aconteça sem que sejam consideradas as críticas já robustas à Justiça de Transição. Em outras palavras, falta a discussão sobre um programa para a Justiça de Transição no Brasil, que defina seu significado e suas estratégias.

Nesse sentido, é fundamental, sobretudo nesse momento histórico, que esse tema seja debatido, ainda mais após o fim da Comissão Nacional da Verdade - e se vislumbra, a partir disso, como manter a pauta da Justiça de Transição na ordem do dia. Isso é imperativo, pois se trata de contribuir para a reorganização e o incremento do uso da Justiça de Transição e de sua estrutura no contexto brasileiro, examinando as críticas a ela, avaliando o uso da categoria e de seus mecanismos no Brasil, sistematizando-os e verificando as especificidades que são determinantes no uso da categoria no país.

\section{CONSIDERAÇÕES FINAIS: MEMÓRIA E VERDADE}

A Justiça de Transição, para ser aplicada de maneira efetiva, deve ser analisada à luz das críticas à categoria e aos seus mecanismos, observando especialmente a necessidade de definir metodologias e usos para contextos específicos. É sob essa perspectiva que o direito à memória e à verdade da ditadura deve ser refletido.

Por ora, há um empenho em garantir esses direitos, por meio do desvelamento dos crimes cometidos contra militantes políticos e mediante a investigação da autoria desses crimes. Porém, nesse diapasão, ficam de fora todas as outras vítimas da ditadura, como os camponeses, os indígenas, as pessoas em situação de rua, minorias étnicas, de gênero e religiosas, etc. Há fortes indícios de que tais 
grupos tenham sofrido duramente com a repressão, o que, inclusive, já consta no relatório da CNV. Entretanto, não foi construída nenhuma memória sobre tais fatos até então, por isso a investigação sobre eles deve ser aprofundada.

Há uma determinação excludente de quem são as vítimas, fato que vai de encontro com a definição de vítima no direito internacional. Isso tem como efeito maquiar o poder exterminador e de fazer "desaparecer" do regime repressivo. De outro lado, a memória e a verdade sobre as relações socioeconômico-empresário-políticas que alavancaram o Estado de exceção se quedam, ainda, de fora das narrativas históricas - quer dizer, estuda-se o efeito (ou seja, a violência), mas não a causa (o contexto político-econômico).

Ainda há outra questão a ser problematizada. A arquitetura da segurança pública existente atualmente no Brasil é, ao menos em parte, legado da ditadura civil-militar brasileira: a estrutura de organização das forças de segurança, a formação dos policiais nas escolas e quartéis, o uso sistemático da tortura como meio de se obter informação, os índices assustadores de execuções sumárias cometidas pelas polícias brasileiras e encobertas por laudos necroscópicos falsos e pela máscara jurídica do "auto de resistência seguido de morte", bem como a permanência do "poder desaparecedor" do Estado, responsável pelo aumento do número de desconhecidos sepultados em valas comuns - ou em valas clandestinas. Atualmente, as vítimas privilegiadas da violência de Estado não são militantes de organizações políticas clandestinas, mas, principalmente, jovens negros, pobres e moradores de áreas periféricas.

Ao abandono social a que está condenada a maioria desses jovens soma-se também o desamparo institucional de suas famílias, que, na maioria absoluta dos casos, não conseguem conhecer a verdade sobre o que ocorreu com seu ente querido ou onde está seu corpo. Isto é, inquéritos são raramente abertos, investigações quase nunca ocorrem de forma séria e efetiva, e os algozes de hoje, como os de ontem, permanecem gozando da impunidade quanto a crimes diversos.

A continuidade da violência de Estado, por meio da manutenção de estruturas repressivas herdadas da ditadura civil-militar, impõe, portanto, a garantia do direito à memória e à verdade aos crimes cometidos por agentes das instituições de segurança, no período pós-democrático, por intermédio de comissões de Estado e de mecanismos de justiça transicional criadas para garantir a memória e a verdade sobre as graves violações ocorridas no período pós-ditatorial. Só assim se pode, efetivamente, caminhar para a consolidação da democracia e para a não repetição das atrocidades, objetivos fundamentais da Justiça de Transição. 
Assim, é imperativa a reflexão sobre como tematizar o direito à memória e à verdade no Brasil, quando da aplicação da Justiça de Transição, de maneira a buscar, da melhor maneira possível, o confrontamento com o legado da ditadura, no sentido de extirpá-lo, "para que não se repita, para que deixe de acontecer".

\section{REFERÊNCIAS BIBLIOGRÁFICAS}

ABrão, Paulo; ToRelly, Marcelo D. Justiça de transição no Brasil: a dimensão da reparação.

In: Abrão, Paulo; Santos, Cecília Macdowell; Torelly, Marcelo D.; SAntos, Boaventura de Sousa (Org.). Repressão e memória política no contexto ibero-brasileiro: estudos sobre Brasil, Guatemala, Moçambique, Peru e Portugal. Brasília: Ministério da Justiça, Comissão de Anistia; Portugal: Universidade de Coimbra, Centro de Estudos Sociais, 2010. p. 24-57.

AIV. CAVv. Transitional justice: justice and peace in situations of transition, n. 65, AIV/n. 19. Advisory Council on International Affairs (AIV) and Advisory Committee on Issues of Public International Law (CAVV), The Hague, 2009.

Amnesty International. Annual report 2013: the state of the world's Human Rights. New York: 2013.

ANDRIEu, Kora. Transitional justice: a new discipline in Human Rights. Online Encycopledia of mass violations, 2010.

ARns, Dom Paulo Evaristo (Org.). Brasil: nunca mais. Petrópolis: Vozes, 1990.

BAGGIO, Roberta Camineiro. A incompletude da transição política brasileira e seus reflexos na cultura jurídica contemporânea: ainda existem perseguidos políticos no Brasil? Revista Anistia, v. 3, p. 244-273, 2010.

BELL, C. Transitional justice, interdisciplinarity and the State of the 'field' or 'non-field'. The International Journal of Transitional Justice, v. 3, p. 5-27, 2009.

Bickford, Louis. Transitional justice. In: The Encyclopedia of Genocide and Crimes against Humanity. Macmillan Reference USA, 2004, v. 3, p. 1045-1047. Disponível em: <www. ictj.org>. Acesso em: 25 maio 2010.

BRASIL. Direito à memória e à verdade. Secretaria Especial de Direitos Humanos, 2009a. Secretaria de Direitos Humanos. PNDH III, 2009b.

Supremo Tribunal Federal. Arguição de Descumprimento de Preceito Fundamental, n. 153. Relator: Min. Eros Grau. Brasília, DF, 28 abr. 2010. . Relatório. Comissão Nacional da Verdade, 2014.

CIDH. Sentença de 24 de novembro de 2010. Julia Gomes Lund e outros (Guerrilha do Araguaia), 2010. 
Codato, Adriano Nervo (Org.). A political transition and democratic consolidation: studies on contemporary Brazil. New York: Nova Science, 2006.

COMPARATo, Bruno. A anistia entre a memória e a reconciliação: dilemas de uma transição política ainda inconclusa. In: Congresso Brasileiro de Sociologia, 14. Trabalho apresentado no GTo5 - Cultura, política e memória, Rio de Janeiro, julho de 2009. Conselho Federal da OAB. ADPF 153. BRASÍllia, 2008.

Fernandes, F. A ditadura em questão. São Paulo, T. A. Queiroz, 1986.

Fletcher, L. E.; Weinstein , H. M.; Rowen, J. Context, timing and the dynamics of transitional justice: a historical perspective. Human Rights Quarterly, v. 31, n. 1, p. 163-220, 2009.

Gaspari, Elio. A ditadura escancarada. v. 2. Coleção As Ilusões Armadas. São Paulo: Companhia das Letras, 2002.

GreIfF, P. A normative conception of transitional justice. Politorbis 5o: dealing with the past. Swiss Federal Department of Foreign Affairs, n. 3, p. 17-29, 2010..

Hainer, H. Helpdesk research report: factors contributing to transitional justice effectiveness. Governance and Social Development Resource Centre, 2011.

HAYNER, Priscilla B. Unspeakable truths: confronting state terror and atrocity. Nova York: Routledge, 2002.

Human Rights Watch. 2013. World Report, Events of 2012.

ICTJ (International Center for Transitional Justice). What is Transitional justice? New York: 2008. Disponível em: <www.ictj.org >. Acesso em: 10 ago. 2010.

LEEBAw, B. A. The irreconcilable goals of transitional justice, Human Rights quarterly. v. 30, n. 1, p. 95-118, February 2008.

McEvoy, Kieran. Letting go of legalism: developing a "thicker" version of transitional justice. In: Mcevoy, Kieran; MCgRegor, Lorna (Ed.). Transitional justice from below: grassroots activism and the struggle for change. Oxford and Portland, Oregon: Hart, 2008. p. 15-45.

Merwe, Hugo Van Der. Delivering justice during transition In: Merwe, Hugo Van Der. Assessing the impact of transitional justice. Washington DC: United States Institute of Peace, 2009.

Merwe, Hugo Van Der; BaXter, Victoria; Chapman, Audrey R. (Ed.). Assessing the impact of transitional justice. Washington DC: United States Institute of Peace, 2009.

Méndez, Juan. Entrevista a Glenda Mezarobba. Revista Internacional de Direitos Humanos-Sur, São Paulo, v. 4, n. 7, 2007.

MEYER, E. P. N. 2012. 303 p. Responsabilização por graves violações de Direitos Humanos na ditadura de 1964-1985: a necessária superação da decisão do Supremo Tribunal Federal na ADPF no 153/DF pelo Direito Internacional dos Direitos Humanos. Tese 
(Doutorado em Direito) - Faculdade de Direito, Universidade Federal de Minas Gerais, Brasília, 2012.

Mezarobba, Glenda. Afinal, o que é uma Comissão da Verdade? Revista Direitos Humanos, n. 5, p. 32-34, abril 2010a.

. O processo de acerto de contas e a lógica do arbítrio. In: Safatle, Vladimir; Teles, Edson. O que resta da ditadura: a exceção brasileira. São Paulo: Boitempo, 2010b. p. 109-119.

MPF (Ministério Público Federal). Crimes da ditadura: relatório preliminar de atos de persecução penal desenvolvidos pelo Ministério Público Federal acerca de graves violações a Direitos Humanos cometidas por agentes do Estado durante a ditadura. Brasília, jan. 2013.

NAGY, R. Transitional Justice as global project: critical reflections. Third World Quarterly, v. 29, ISS. 2, 2008.

Network for Social Justice and Human Rights. Human Rights in BraziL 2012, a report by the network for social justice and Human Rights. São Paulo, 2012.

NEV (Núcleo de Estudos da ViolÊNCia/USP). Continuidade autoritária e construção da democracia. Relatório final de pesquisa. São Paulo, 1999.

. $5^{\circ}$ Relatório Nacional sobre os Direitos Humanos no Brasil 2001-201o. São Paulo, 2012.

Okello, Moses Chrispus. Elevating transitional local justice or crystalizing global governance. In: SHAW, Rosalind; WALdORf, Lars; HAZAN, Pierre (Ed.). Localizing transitional justice: interventions and priorities after mass violence. Stanford: Stanford University, 2010.

Olsen, Tricia; PAYne, Leigh; ReIter, Andrew. Transitional Justice in balance. Washington DC: United States Institute of Peace, 2010a.

The justice balance: when transitional justice improves Human Rights and democracy. Human Rights Quarterly, v. 32, n. 4, p. 980-1007, $2010 b$.

Palmer, N.; Clark, P.; Granville, D. Critical perspectives in transitional justice. series on transitional justice. Intersentia, Antwerp, 2012.

PASTORAL CARCERÁRIA. Relatório sobre a tortura: uma experiência de monitoramento dos locais de detenção para prevenção da tortura. São Paulo, 2010.

PAYNE, L. A. Unsettling accounts: neither truth nor reconciliation in confessions of state violence. Edited by Neil L. Whitehead, Jo Ellen Fair and Leigh A. Payne, The cultures and practice of violence series. Durham: Duke University Press, 2008.

Pereira, Anthony. Ditadura e repressão: o autoritarismo e o estado de direito no Brasil, no Chile e na Argentina. Tradução de Patrícia de Queiroz Carvalho Zimbres. São Paulo: Paz e Terra, 2010. 
QuinalHA, Renan. 2012.173 p. Justiça de transição: contornos de um conceito. Dissertação

(Mestrado em Filosofia e Teoria Geral do Direito) - Faculdade de Direito da USP, 2012.

RamjI-Nogales, J. Designing bespoke transitional justice: a pluralist process approach.

Michigan Journal of International Law, v. 32, p. 1-72, 2010.

Safatle, Vladimir; Teles, Edson. O que resta da ditadura: a exceção brasileira. São Paulo:

Boitempo, 2010. p. 237-252.

Teitel, Ruti. Transitional justice genealogy. Harvard Human Rights Journal, v. 16, p. 69-94, 2003.

United Nations Human Rights Council. Report of the Working Group on the Universal Periodic Review, Brazil, A/HRC/21/11, 9 July 2012.

United Nations Security Council. The rule of law and transitional justice in conflict and post-conflict societies. New York: Report of the Secretary-General to the Security Council, 23 August 2004. S/2004/616.

VINCK, P.; PHAM, P. N. Outreach evaluation: the international criminal court in the Central African Republic. International Journal of Transitional Justice, v. 4, n. 3, p. 421-442, 2010.

Weichert, M. O financiamento de atos de violação de Direitos Humanos por Empresas durante a ditadura brasileira. Revista Acervo, Local de publicação 21, nov. 2011. Disponível em: <revistaacervo.an.gov.br/seer/index.php/info/article/view/92>. Acesso em: 12 JAN. 2012.

ZeLIC, M. Povos indígenas e ditadura militar: subsídios à Comissão Nacional da Verdade 1946-1988. Relatório Parcial 01, 30/11/2012.

ZyL, Paul Van. Promovendo a Justiça Transicional em sociedades pós-conflito. Revista da Anistia política e Justiça de Transição, Brasília, n. 1, p. 32-55, jan.-jul. 2009. 